\title{
Surveillance-based evidence: elimination of schistosomiasis as a public health problem in the Peoples' Republic of China
}

Jing Xu1 ${ }^{1}$, Shi-Zhu Li ${ }^{1}$, Li-Juan Zhang ${ }^{1}$, Robert Bergquist ${ }^{2}$, Hui Dang ${ }^{1}$, Qiang Wang ${ }^{1}$, Shan LV ${ }^{1}$, Tian-Ping Wang ${ }^{3}$, Dan-Dan Lin ${ }^{4}$, Jian-Bing Liư ${ }^{5}$, Guang-Hui Ren ${ }^{6}$, Kun Yang ${ }^{7}$, Yang Liư ${ }^{8}, Y_{i}$ Dong $^{9}$, Shi-Qing Zhang ${ }^{3}$ and Xiao-Nong Zhou ${ }^{1 *}$

\begin{abstract}
Background: A steady progress on schistosomiasis control in the Peoples' Republic of China (P.R. China) was achieved and broadened into the twelve-year medium and long term national plan (MLNP) which marled the implementation of an integrated control strategy across all endemic areas in P.R. China in 2004. To understand the endemic trends of schistosomiasis to assess the effectiveness of an integrated strategy, we conducted an analysis of schistosomiasis surveillance data spanned from 2005 to 2015.

Methods: The schistosomiasis sentinel surveillance data from sentinel sites were collected and analyzed from 2005 to 2015. In these sentinel sites, residents aged 6 years or above were screened annually by indirect hemagglutination assay (IHA), while only antibody positives were followed by stool examination either Kato-katz method (KK) and/or hatching technique (HT). Domestic animals raised in sentinel sites were examined by HT for confirming the infection of schistosomes. Snail investigation was conducted each year through systematic sampling method combined with environmental sampling method. The snails collected from field were tested by microscopic dissection method. The infection rates of schistosomes in residents, domestic animals and snails, as well as the indicators reflecting the snails' distribution were calculated and analyzed. ANOVA analysis was used to examine the changes of the number of eggs per gram feces in population and Chi-square test was used to examine any change in proportions among groups.

Results: A total of 148902 residents from sentinel sites attended this study and 631676 blood samples were examined by $I H A$ test during the 11 covered years. The annual average antibody positive rates presented a significant decrease trends, from $17.48 \%$ (95\% Cl: $17.20-17.75 \%)$ in 2005 to $5.93 \%$ (95\% Cl: $5.71-6.15 \%)\left(X^{2}=8890.47\right.$, $P<0.001)$ in 2015. During 2005-2015, the average infection rate of schistosomes in residents declined from 2.07\% (95\% Cl: $1.96-2.17 \%$ ) to $0.13 \%$ (95\% Cl: $0.09-0.16 \%$ ), accompanied by significant decrease of infection intensity in population. In 2015, the stool positives were only found in farmers, fishermen and boatmen with infection rate of (Continued on next page)
\end{abstract}

\footnotetext{
* Correspondence: zhouxn1@chinacdc.cn

${ }^{1}$ National Institute of Parasitic Diseases, Chinese Center for Disease Control and Prevention, WHO Collaborating Centre for Tropical Diseases, Chinese

Center for Tropical Disease Research, Shanghai 200025, People's Republic of

China

Full list of author information is available at the end of the article
}

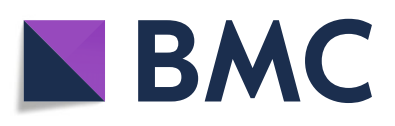

( ) The Author(s). 2020 Open Access This article is licensed under a Creative Commons Attribution 4.0 International License, which permits use, sharing, adaptation, distribution and reproduction in any medium or format, as long as you give appropriate credit to the original author(s) and the source, provide a link to the Creative Commons licence, and indicate if changes were made. The images or other third party material in this article are included in the article's Creative Commons licence, unless indicated otherwise in a credit line to the material. If material is not included in the article's Creative Commons licence and your intended use is not permitted by statutory regulation or exceeds the permitted use, you will need to obtain permission directly from the copyright holder. To view a copy of this licence, visit http://creativecommons.org/licenses/by/4.0/. The Creative Commons Public Domain Dedication waiver (http://creativecommons.org/publicdomain/zero/1.0/) applies to the data made available in this article, unless otherwise stated in a credit line to the data. 


\begin{abstract}
(Continued from previous page)
$0.16 \%$ (95\% Cl: $0.11-0.20 \%), 0.17 \%$ (95\% Cl: 0-0.50\%) respectively. The infection rate of schistosomes in domestic animals dropped from 9.42\% (538/5711, 95\% Cl: 8.66-10.18\%) to 0.08\% (2/2360, 95\% Cl: 0-0.20\%) from 2005 to 2015. Infections were found in eight species of domestic animals at the beginning of surveillance while only two cattle were infected in 2015. Totally 98 ha of new snail habitats were found, while 94.90\% (93/98) distributed in lake and marshland regions. The percentage of frames with snails decreased from 16.96\% (56 884/33 5391, 95\% Cl: $16.83-17.09 \%)$ in 2005 to $4.28 \%$ (18 121/423 755, 95\% Cl: 4.22-4.34\%) in 2014, with a slightly increase in 2015. Meanwhile, the infection rate of schistosomes in snails was decreased from $0.26 \%$ (663/256 531, 95\% Cl: 0.24-0.28\%) to zero during 2005-2015.

Conclusions: The infection rate of schistosomes declined significantly, providing evidence that the goal of the MLNP was achieved. Elimination of schistosomiasis as a public health problem defined as WHO was also reached in P.R. China nationwide. Surveillance-response system should be improved and strengthened to realize the final goal of schistosomiasis elimination.
\end{abstract}

Keywords: Schistosomiasis, Surveillance, Infection rate, Elimination, China

\section{Background}

Schistosomiasis is a globally distributed disease caused by three major Schistosoma species: S. mansoni, S. haematobium and S. japonicum [1], all depending on intermediate snail hosts to complete their life cycles. Humans get infection when contact with freshwater containing cercaria of schistosomes. In contrast to other schistosome species, S. japonicum is a zoonotic species with a wide spectrum of wild and domestic animals serving as reservoir hosts [2]. Among countries with areas endemic for schistosomiasis japonica, the Peoples' Republic of China (P.R. China) had a very high disease burden in the 1950s with 11.6 million individuals and 1.2 million cattle infected with S. japonicum [3, 4].

High priority for schistosomiasis control is always given by the central government in P.R. China exemplified by the slogan of "Must eliminate schistosomiasis" issued in 1955 and poems of "Farewell to the God of Plague" written by the Chairman Mao Zedong [5]. Consecutive national programme was conducted with implementation of disease elimination strategy emphasized on snail control and later morbidity control strategy focused on chemotherapy, adapting to epidemiological insights, technological advances and economic status at that time before the new millennium [6,7]. Although significant decrease of snail habitats and morbidity of schistosomiasis in residents and livestock occurred during 1992-2001 with the implementation of World Bank Loan Project for schistosomiasis control, infection and reinfection were unavoidable due to the continued transmission cycle of schistosomiasis [8].

The huge flooding along the Yangtze River that occurred in 1998 contributed to increasing numbers of infected people and further modulated by changes of economic, social and other factors at the beginning of twenty-first Century [3]. When this trend was confirmed, to protect human beings, a medium and long term national plan (MLNP) for schistosomiasis control was initiated in 2004, aiming at reaching morbidity control (both infection rates of schistosomes in residents and domestic animals less than 5\%) by 2008 and transmission control (both infection rates of schistosomes in residents and domestic animals below $1 \%$, and no infected snails detected in two consecutive years) by 2015 in all endemic villages, according to the criteria of schistosomiasis control and elimination defined by the Chinese government [6]. Obviously,the indicators to assess the stage of transmission control are much stricter than the threshold of eliminating schistosomiasis as a public health problem defined by WHO as the infection rate of high-intensity $<1 \%$ in all sentinel sites $[9,10]$. Meanwhile, a comprehensive control strategy aiming to block the transmission of schistosomiasis was put forward through pilots first and then expanded in MLNP $[6,9]$.

To better understand the trends of schistosomiasis transmission and evaluate the effectiveness of the comprehensive control strategy, a systematic surveillance platform was constructed since 2005 [11] . Except for routine case reporting, the sentinel sites were enlarged from 20 to 80 , covering more range and presenting all categories of endemic villages $[12,13]$. In this article, we describe the changes of infection rates of schistosomes in human beings, domestic animals and snails, as well as the transmission features spanned the years from 2005 to 2015, using schistosomiasis sentinel surveillance data.

\section{Methods}

\section{National sentinel surveillance sites}

During 2005-2015, schistosomiasis endemic villages cross P.R. China were selected by modified stratified sampling method based on their eco-epidemiological features. In each provinces, the endemic areas were categorized by environmental ecosystems of snail infested 
area, including 1) lake and marshland region, 2) waterway networks in the plain region, 3) hilly and mountainous region [14]. Villages presenting local highest endemic situations were randomly selected as the sentinel sites, concerning the recent 3 years of epidemiological data. In phase of 2005-2010, 80 sentinel sites were distributed in nine endemic provinces and Chongqing City, the later regarded having the transmission potential of schistosomiasis due to the construction of the Three Gorges Dam. Due to the decreased compliance rate receiving examination and treatment, sentinel sites were adjusted in 2011 according to local situation. 69 sites remained the same during two phases, while other villages were adjusted. The number of sentinel sites accounted about $0.2 \%$ of total endemic villages nationwide. General information of selected sentinel sites including number of residents, ecological features, longitude and latitude of villages were collected and recorded.

\section{Surveillance of human population}

Annual cross-sectional surveys were carried out in October or November in all sentinel villages after the transmission season. All residents aged 6 years or above were enrolled and a simple questionnaire was distributed to collect general demographic information. One blood sample over $250 \mu \mathrm{l}$ was collected from each participant and centrifuged to separate sera. The obtained sera samples were tested by indirect hemagglutination assay (IHA, Anji Pharmaceutical Technology Co., Ltd) according to the manufacture's protocol. The titer in the tested sera was recorded as one dilution before that which yielded a clear, sharp dark spot similar to that in the negative control wells. Titers were expressed as reciprocal values. Titers of $\geq 10$ indicated a positive result [15].

At least $30 \mathrm{~g}$ of stool was collected from each IHApositives and subjected to fecal examination. During 2005-2010, Kato-Katz thick smear technique (KK) was the only method to confirm an infection. While in 2011-2015, hatching technique (HT) was conducted in parallel with KK for one fecal sample to increase the detection rate $[16,17]$. Briefly, three thick smear from each stool were prepared and read by experienced technicians. The number of schistosome eggs detected from each KK slide was recorded. The remaining fecal specimen was tested by miracidium HT. Observation was made at $4,8,12 \mathrm{~h}$ after hatching. Residents that were positive for KK and/or HT (egg positive and/or miracidium positive) were defined as parasitological positive.

\section{Animal surveillance}

Domestic animals including bovines, pigs, goats, dogs, etc. raised in each sentinel sites were investigated simultaneously as the survey conducted on humans. The minimum sample size of each kind of domestic animals was 60 in each village (If the number of raised animals less than 60, all animals would be examined). Stools from domestic animals were collected and then examined annually by HT after peak transmission season [16]. The result can be defined as positive if miracidium was observed.

\section{Snail surveillance}

The snail survey was conducted annually in surroundings where have or potentially have snails infested, by a square frame made by iron wire with $0.1 \mathrm{~m}^{2}$ area through a systematic sampling method combined with environmental sampling method [16]. All snails within the frames were collected, counted and brought to the laboratory to be examined in a dissecting microscopy to identify the infection status and whether they were alive or not. The snail was determined as infected one if the sporocyst and/or cercaria of schistosome was detected in the soft tissues of dissected snail.

\section{Data management and statistical analysis}

Surveillance activities were conducted by Center for Disease Control (CDC) or Schistosomaisis Control Station at county level. Annual data reflecting the endemic situation of schistosomiasis were collected and entered into computer in a standardized manner and sent to National Institute of Parasitic Diseases, the Chinese Center for Disease Control and Prevention. Quantitative data were analyzed descriptively using the statistical software SPSS (version 13.0, SPSS Inc., Chicago, USA).

The trends of infection status of schistosomes were measured by infection rates of schistosomes in human residents, domestic animals and snails. Human infection rate in a sentinel village was calculated by the IHA positive rate (No. sero-positives/No. examined by IHA) times parasitological positive rate (No. positives in KK or HT/No. received stool examination) [18]. The number of eggs per gram feces (EPG) of infected residents determined by KK was calculated with the total number of eggs counted in three KK slides from one stool sample multiplying by eight. Infection rate of schistosomes in domestic animals was calculated by No. positives in HT/No. animals received stool examination [18]. For snails, infection rate of schistosomes in snails was determined as No. infected snails/No. dissected snails. Snail infested area, area with infected snails, area of new snail habitats were calculated according to the guidelines of schistosomiasis control handbook in China $[16,19]$. The area reflecting the distribution of snails was expressed as length (meters) multiplied by width (meters). The length and width were determined based on the largest distance between two frames which found live snails or infected snails in the surveyed environments [19]. Confidence 
intervals $(C I)$ were calculated using standard formulas based on the binomial distribution. ANOVA analysis was used to examine the changes of EPG in population and Chi-square test was used to examine any change in proportions over time. $P$-values less than 0.05 were considered to be statistically significant.

\section{Results}

\section{General information of sentinel sites}

In phase of 2005-2010, among 80 sentinel sites, 53 were featured as lake and marshland regions, 23 were located in hilly and mountainous regions while the left four were located in waterway network in plain region, covering 130 703 residents. In second phase, one site characterized as waterway network in plain region was dropped from Jiangsu Province and one more each in Guangdong Province (waterway network in plain region) and Guangxi Zhuang Autonomous Region (hilly and mountainous region) were added respectively. The total number of the residents in sentinel sites in 2011 was 84 382. The geographical distribution of the sentinel sites is depicted in Fig. 1.

\section{Trends in residents}

A total of 148902 residents from sentinel sites attended this study and 631676 blood samples were examined by IHA test during the 11 covered years. The ratio of males to females was $0.96: 1$ (72 689 males/75 922 females), while gender information of 291 blood providers was missed. The annual average antibody positive rates presented a significant decrease trends, from 17.48\% (95\% CI: $17.20-17.75 \%$ ) in 2005 to $5.93 \%$ (95\% CI: $5.71-$ 6.15\%) $\left(\chi^{2}=8890.47, P<0.001\right)$ in 2015 (Table 1).

Among 63702 antibody positives detected during 2005-2015, 95.89\% (61 081/63 702) received stool examination. By KK method, the number of egg positives was decreased from 1447 in 2005 to 36 in 2015, with mean EPG decreased significantly from $12.37 \pm 124.62$ to $1.14 \pm 14.96(\mathrm{~F}=2.30, P=0.01)$. In 2015 , only one infected resident had EPG of 512, in the range of high infection intensity. During 2011-2015, HT was conducted in parallel with KK method, with 507 positives and 473 positives totally detected by each method. Combined the results of $\mathrm{KK}$ and $\mathrm{MH}$ methods, totally 4656 of stool samples were determined as parasitological positives during 2005-2015, with a significant declined trend (Table 1).

In combination of the result of serological test and parasitological tests, the infection rate of schistosomes in residents declined from $2.07 \%$ (95\% CI: $1.96-2.17 \%$ ) in 2005 to $0.13 \%$ (95\% CI: $0.09-0.16 \%$ ) in 2015 at a high level of statistical significance $\left(X^{2}=751.24, P<0.001\right)$ (Table 1). In 2005, 1447 stool positives distributed in $86.25 \%(69 / 80)$ sentinel villages, while 55 stool positives in 2015 were found in $27.16 \%(22 / 81)$ villages. Based on village level, the highest infection rate was $13.34 \%$ in 2005 and $0.87 \%$ in 2015, both from the lake and marshland regions of Hunan Province (Fig. 2).

The infection rates of schistosomes in residents classified by gender, age, occupation, eco-epidemiological

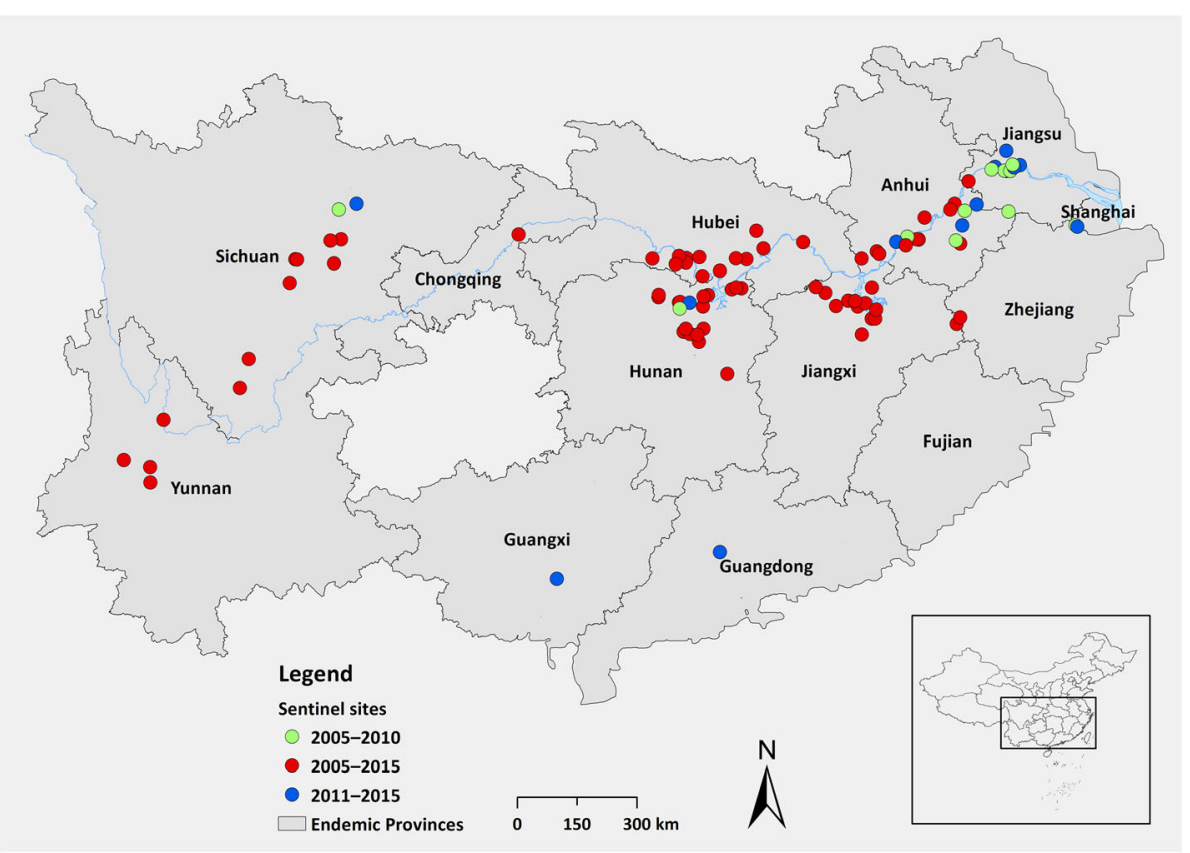

Fig. 1 The geographical distribution of sentinel sites during 2005-2015 
Table 1 Changes of infection rates of schistosomes in population during 2005-2015 in sentinel sites

\begin{tabular}{|c|c|c|c|c|c|c|c|c|c|c|}
\hline \multirow[t]{2}{*}{ Phase } & \multirow[t]{2}{*}{ Year } & \multicolumn{3}{|l|}{ IHA test } & \multirow{2}{*}{$\begin{array}{l}\text { No. stool } \\
\text { samples } \\
\text { received } \\
\text { examination }{ }^{\text {a }}\end{array}$} & \multicolumn{2}{|l|}{ Kato-Katz } & \multirow{2}{*}{$\begin{array}{l}\text { No. HT } \\
\text { positives }\end{array}$} & \multirow{2}{*}{$\begin{array}{l}\text { No. } \\
\text { parasitological } \\
\text { positives }\end{array}$} & \multirow{2}{*}{$\begin{array}{l}\text { Infection rate } \\
(\%, 95 \mathrm{Cl})\end{array}$} \\
\hline & & $\begin{array}{l}\text { No. sera } \\
\text { samples } \\
\text { examined }\end{array}$ & $\begin{array}{l}\text { No. } \\
\text { positives }\end{array}$ & $\begin{array}{l}\text { Antibody positive } \\
\text { rate, } \%(95 \% \text { Cl) }\end{array}$ & & $\begin{array}{l}\text { No. KK } \\
\text { positives }\end{array}$ & $\begin{array}{l}\text { Arithmetic mean } \\
E P G(\text { mean } \pm S D)\end{array}$ & & & \\
\hline \multirow[t]{6}{*}{ | } & 2005 & 72595 & 12686 & $17.48(17.20-17.75)$ & 12226 & 1447 & $12.37 \pm 124.62$ & - & 1447 & $2.07(1.96-2.17)$ \\
\hline & 2006 & 64336 & 8770 & $13.63(13.37-13.90)$ & 8406 & 961 & $10.95 \pm 88.34$ & - & 961 & $1.56(1.46-1.65$ \\
\hline & 2007 & 60535 & 7484 & $12.36(12.10-12.63)$ & 7215 & 537 & $3.16 \pm 22.88$ & - & 537 & $0.92(0.84-1.00$ \\
\hline & 2008 & 63202 & 6670 & $10.55(10.31-10.79)$ & 6104 & 416 & $3.03 \pm 25.44$ & - & 416 & $0.72(0.65-0.79$ \\
\hline & 2009 & 62039 & 5523 & $8.90(8.68-9.13)$ & 5293 & 304 & $2.71 \pm 22.89$ & - & 304 & $0.51(0.46-0.57)$ \\
\hline & 2010 & 59311 & 5636 & $9.50(9.27-9.74)$ & 5358 & 314 & $4.93 \pm 143.59$ & - & 314 & $0.56(0.50-0.62$ \\
\hline \multirow[t]{5}{*}{$\|$} & 2011 & 54550 & 4249 & $7.79(7.56-8.01)$ & 4155 & 194 & $1.94 \pm 16.21$ & 222 & 289 & $0.54(0.48-0.60$ \\
\hline & 2012 & 53040 & 3869 & $7.29(7.07-7.52)$ & 3759 & 136 & $1.47 \pm 14.76$ & 102 & 173 & $0.34(0.29-0.38$ \\
\hline & 2013 & 50648 & 3349 & $6.61(6.4 .40-6.83)$ & 3163 & 75 & $0.70 \pm 6.54$ & 95 & 112 & $0.23(0.19-0.28$ \\
\hline & 2014 & 47457 & 2858 & $6.02(5.81-6.24)$ & 2802 & 32 & $0.41 \pm 6.38$ & 42 & 48 & $0.10(0.07-0.13$ \\
\hline & 2015 & 43963 & 2608 & $5.93(5.71-6.15)$ & 2600 & 36 & $1.14 \pm 14.96$ & 46 & 55 & $0.13(0.09-0.16$ \\
\hline Total & & 631676 & 63702 & - & 61081 & 4452 & - & 507 & 4656 & - \\
\hline
\end{tabular}

anly done in individuals with positive IHA results

IHA Indirect hemagglutination assay, KK Kato-katz, EPG Eggs per gram feces, $H T$ Hatching technique, $\mathrm{Cl}$ confidence intervals

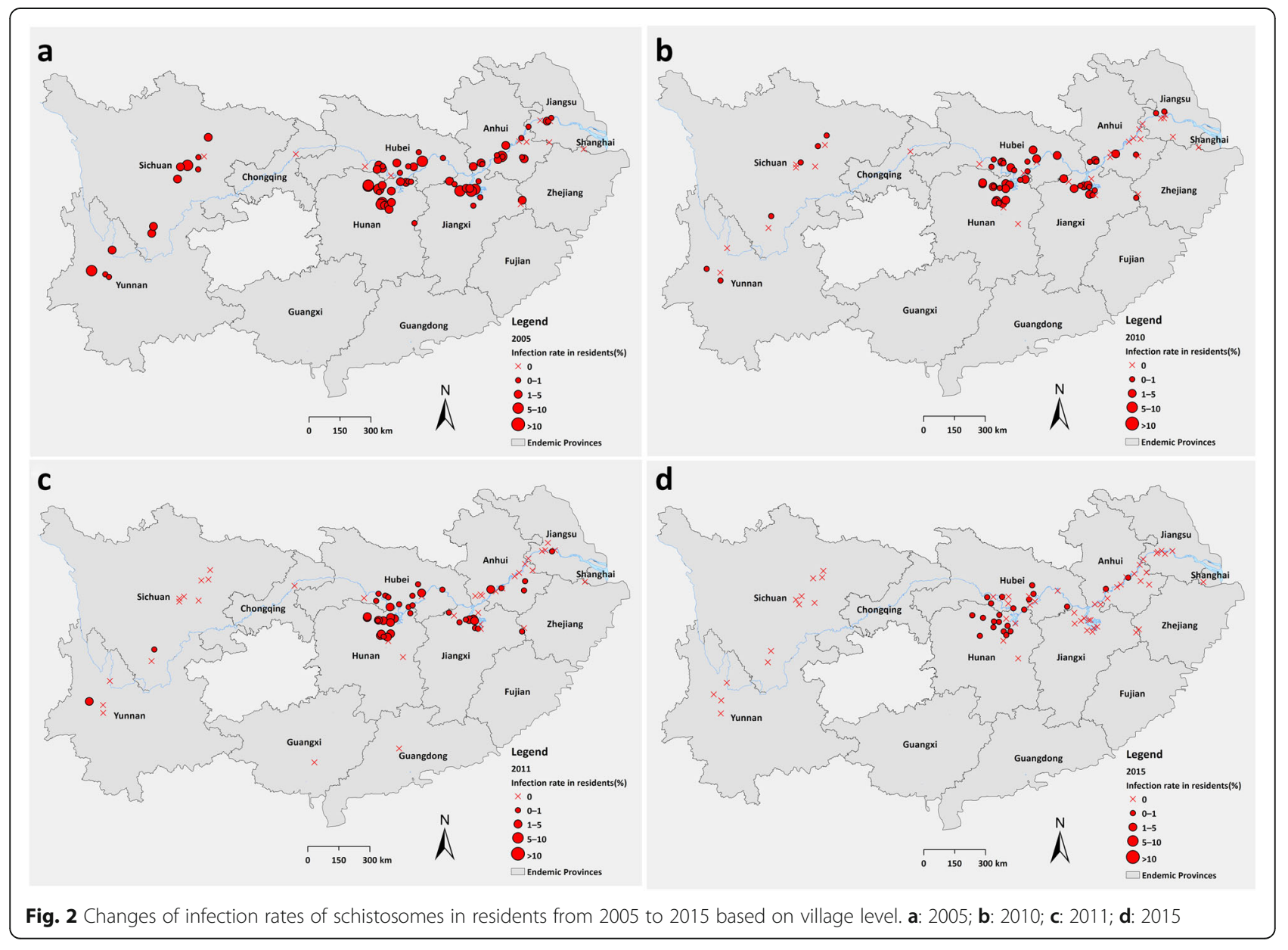


types were shown in Fig. 3. The infection rate in males was decreased from 2.69\% (95\% CI: 2.52-2.85\%) in 2005 to $0.20 \%$ (95\% CI: $0.14-0.26 \%$ ) in 2015 , and in females decreased from $1.46 \%$ (95\% CI: $1.34-1.58 \%$ ) to $0.05 \%$ (95\% CI: $0.02-0.08 \%$ ). Males generally presented a higher infection rate than the females during 2005-2015 (Fig. 3a). The infection rate of schistosomes in residents peaked in the elder age group and decreased with time went by (Fig. 3b). The population group aged 40-49, 50-59 years old presented the highest infection rate of 2.72\% (95\% CI: $2.48-3.06 \%$ ), $2.66 \%$ (95\% CI: $2.33-2.93 \%$ ) in 2005 and decreased to $0.15 \%$ (95\% CI: $0.07-0.22 \%$ ), $0.17 \%$ (95\% CI: $0.09-0.25 \%)$ in 2015 respectively. Analyzed by occupation, fishermen and boatmen, and farmers were the major population infected with schistosomes with the highest infection rates almost each year (Fig. 3c). In 2015, the stool positives were only found in farmers, fishermen and boatmen with infection rate of 0.16\% (95\% CI: $0.11-0.20 \%$ ), 0.17\% (95\% CI: 0-0.50\%) respectively. By eco-endemic types of sentinel sites, lake and marshland regions always preformed the highest infection rate, but also decreased significantly from $2.53 \%$ (95\% CI: $2.39-2.67 \%)$ in 2005 to $0.17 \%$ (95\% CI: $0.13-0.22 \%$ ) in 2015, while the infection rate of schistosomiasis in hilly and mountainous regions reached zero since 2014 and no infection was found in residents from water-way network regions since 2005 (Fig. 3d).

\section{Trends in domestic animals}

During 2005-2015, total 37822 domestic animals received stool examination by HT and 1203 positives were determined. The average infection rate of schistosomes in domestic animals declined from 9.42\% (538/5711, 95\% CI: 8.66-10.18\%) in 2005 to $0.08 \%(2 / 2360,95 \%$ CI: $0-0.19 \%)$ in 2015 significantly $\left(\chi^{2}=233.13, P<0.001\right)$ (Table 2). In 2005, infected domestic animals were found in 57 villages among 72 villages where had livestock raised. The highest infection rate reached $65.91 \%$ (29/44, 95\% CI: 51.90-79.92\%) in a sentinel site within Yueyang City of Hunan Province. In 2015, there were only 44 villages raising domestic animals and only two infected cattle were detected in two separate sentinel sites of Hunan Province (Fig. 4).

At the beginning of the sentinel surveillance, the infection rate of schistosomes in domestic animals was very high both in lake and marshland regions, hilly and mountainous regions, with the value of $11.17 \%$ (300/ 2685, 95\% CI: 9.98-12.36\%) and 8.05\% (238/2955, 95\% CI: 7.07-9.03\%) in 2005 respectively. However, the infection rates of schistosomes in domestic animals decreased zero in hilly and mountainous regions since 2013. And

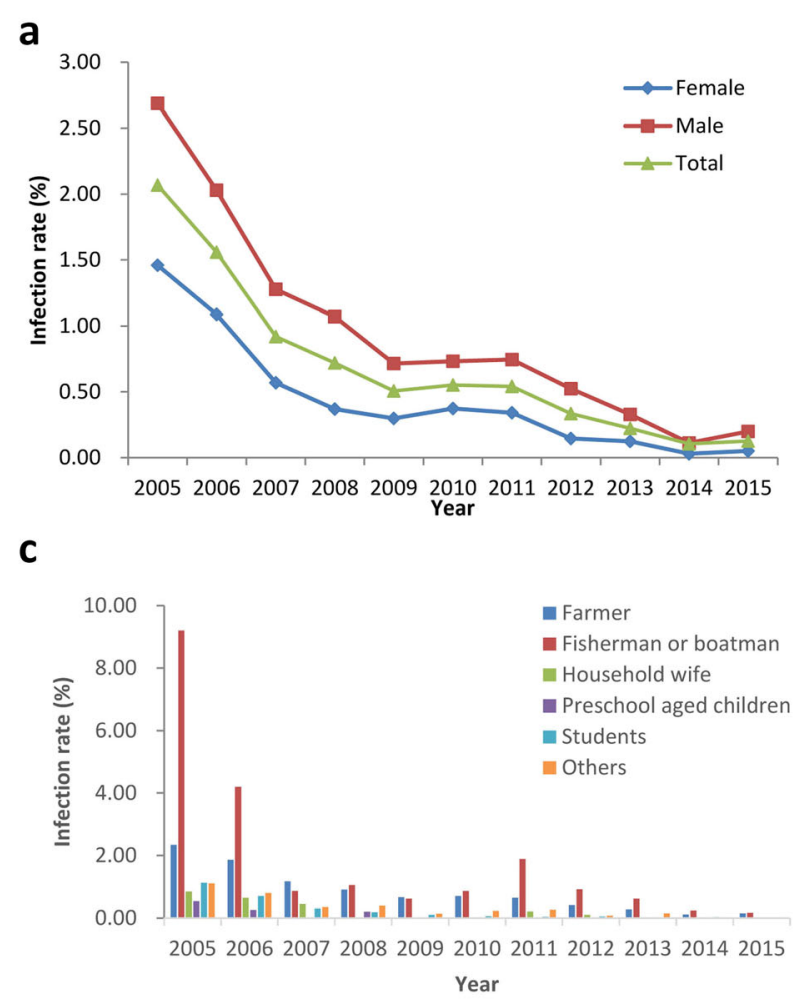

b

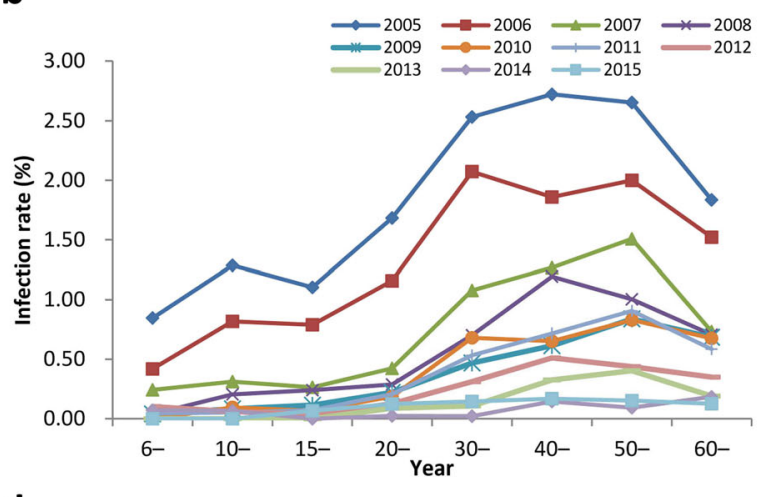

d

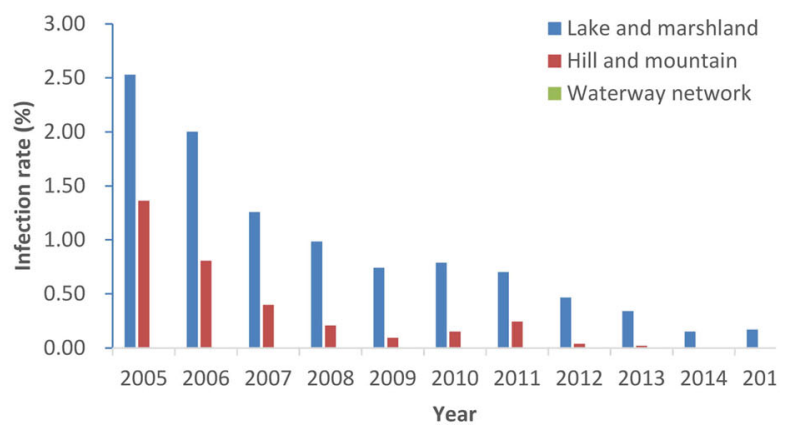

Fig. 3 Changes of infection rates of schistosomes in residents from 2005 to 2015 by strata. a: by gender; b: by age; c: by occupation; d: by eco-epidemiology 
Table 2 Changes of infection rates of schistosomes in domestic animals during 2005-2015 in sentinel sites

\begin{tabular}{lllll}
\hline Phase & Year & No. examined & No. positives & Infection rate, \% (95\% C) \\
\hline & 2005 & 5711 & 538 & $9.42(8.66-10.18)$ \\
& 2006 & 5365 & 318 & $5.93(5.30-6.56)$ \\
& 2007 & 3693 & 107 & $2.90(2.36-3.44)$ \\
& 2008 & 3486 & 58 & $1.66(1.24-2.09)$ \\
& 2009 & 3538 & 65 & $1.84(1.39-2.28)$ \\
& 2010 & 3225 & 53 & $1.64(1.20-2.08)$ \\
|| & 2011 & 3712 & 36 & $0.97(0.65-1.29)$ \\
& 2012 & 2670 & 20 & $0.75(0.42-1.08)$ \\
& 2013 & 1969 & 5 & $0.25(0.03-0.48)$ \\
& 2014 & 2093 & 1 & $0.05(0-0.14)$ \\
Total & 2015 & 2360 & 2 & $0.08(0-0.20)$ \\
\hline
\end{tabular}

no infection of schistosomes was found in domestic animals in four sentinel sites featured by waterway network in plain regions during 2005-2015 (Fig. 5a). In 2005, the highest infection rate of schistosomiasis in cattle was 10.61\% (515/4853, 95\% CI: 9.74-11.48\%), and positives were also found in other seven species including goat, pig, horses etc. with infection rates in the range of 0.55$4.11 \%$. Since 2012 , infections were only detected in cattle (Fig. 5b).

\section{Trends in snails}

Snail investigation was conducted in 79351 ha of areas cumulatively during 2005-2015. Totally 4119055 frames were set for snail's investigation and 1350028 living snails were found in 350712 set frames. By dissection method, totally 2408 infected snails were found. The area of snails' habitats varied from 5150 ha to 3859 ha in a decreased trend as time went by. Totally 98 ha of new snail habitats were found in the period of 20052010, while $94.90 \%$ (93/98) distributed in lake and marshland regions. The area with infected snails decreased from 482 ha in 2005 to zero since 2014 in all sentinel sites.

The percentage of frames infested with snails decreased from 16.96\% (56 884/335391, 95\% CI: $16.83-$ $17.09 \%)$ in 2005 to $4.28 \%$ (18 121/423755, 95\% CI: 4.22-4.34\%) in 2014, with a slightly increase in 2015. Meanwhile, the infection rate of schistosomes in

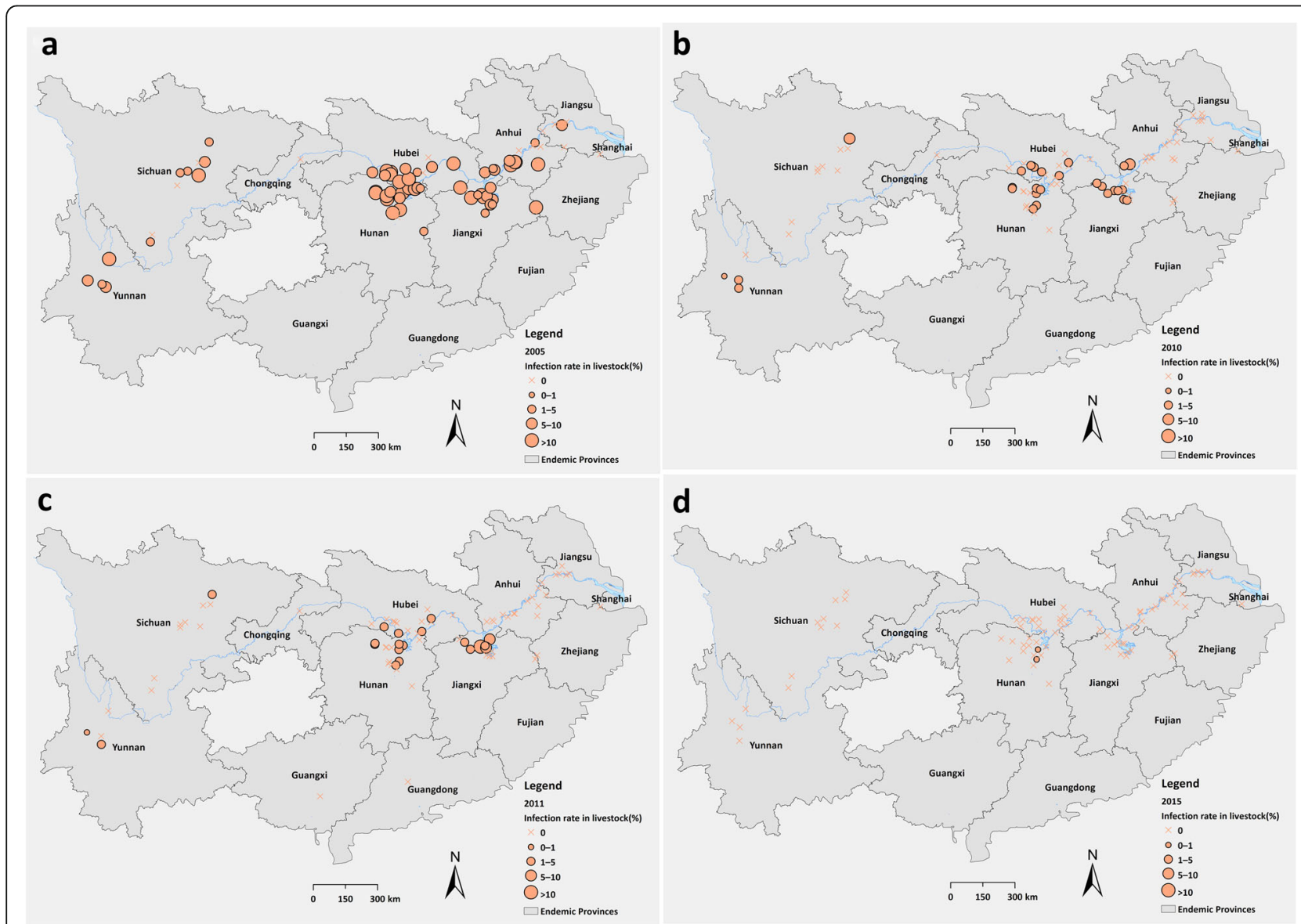

Fig. 4 Changes of infection rates of schistosomes in domestic animals from 2005 to 2015 based on village level. a: 2005; b: 2010; c: 2011 ; d: 2015 

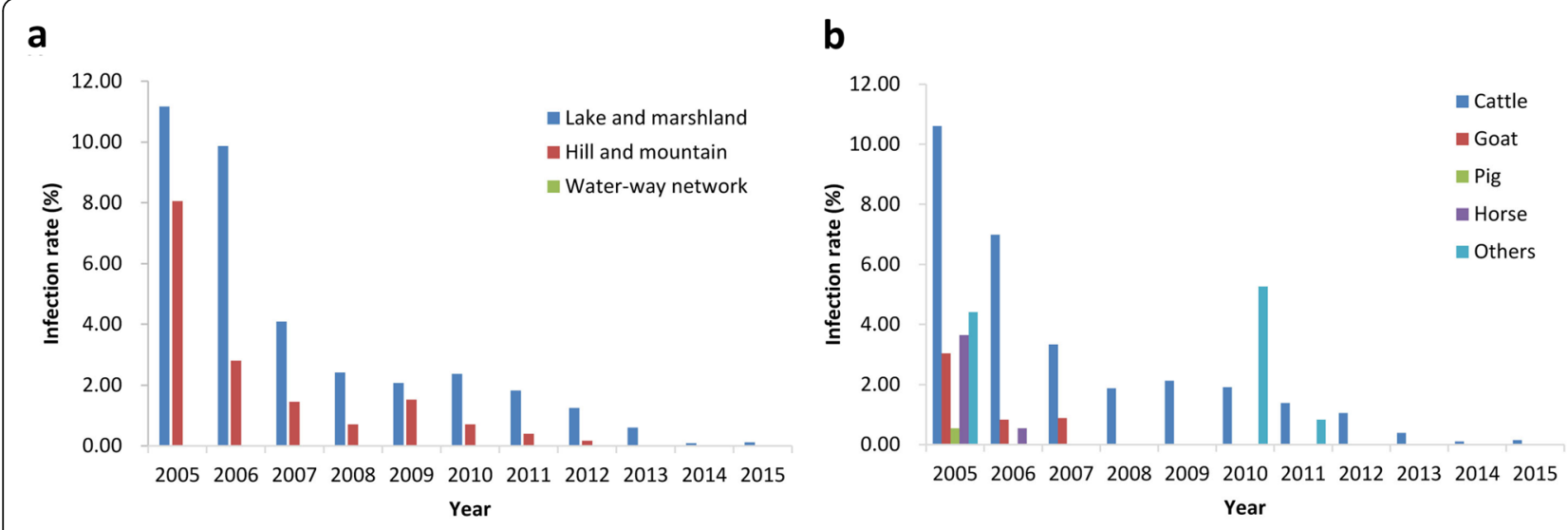

Fig. 5 Changes of infection rates of schistosomes in domestic animals by eco-epidemiological and species strata. a: by eco-epidemiology $\mathbf{b}$. by species strata

snails was decreased year by year significantly with $P<0.001$ (Table 3). In 2005, among 50 villages found infected snails, 40 distributed in lake and marshland regions while 10 in hilly and mountainous regions, with the highest infection rate of $14.04 \%(8 / 57,95 \%$ CI: $5.02-23.06 \%$ ) occurred in a village from Hubei province. There was no positive snail found through traditional dissection method in 2014 and 2015 (Fig. 6).

\section{Discussion}

Schistosomiasis is a water borne communicable disease and mainly endemic in the poor and rural areas of the world, regarded as a disease difficult to be controlled. Due to the reduction of the cost of praziquantel, an effective drug for treatment, and increased funding for schistosomiasis control programmes in recent decades, the number of people receiving preventive chemotherapy with praziquantel increased worldwide [20]. Although the argument on the goal set for schistosomiasis elimination continues [21, 22], opinions tend to be consistent that schistosomiasis is one of diseases being potentially eliminated in countries with low endemicity, adequate resources and political commitments provided [23, 24]. With the implementation of the twelve-year's MLNP in P.R. China, the annually national reports showed that the number of estimated cases had been dramatically decreased from 798762 in 2005 to 77194 in 2015, with a reduction rate of $90.34 \%[25,26]$. The results of our sentinel surveillance data in this article provided evidence that the infection and transmission risk of schistosomiasis was reduced significantly in P.R. China. It is feasible to eliminate schistosomiasis as a public health problem at a country level and transmission interruption could be reached at a regional or country level after application of intensive and comprehensive approaches.

Table 3 Results of snail survey during 2005-2015 in sentinel sites

\begin{tabular}{|c|c|c|c|c|c|c|c|c|c|c|c|}
\hline $\begin{array}{l}\text { Surveillance } \\
\text { phase }\end{array}$ & Year & $\begin{array}{l}\text { No. area } \\
\text { surveyed } \\
\text { (ha) }\end{array}$ & $\begin{array}{l}\text { No. area with } \\
\text { infested snails } \\
\text { (ha) }\end{array}$ & $\begin{array}{l}\text { No. area of } \\
\text { new snail } \\
\text { habitat(ha) }\end{array}$ & $\begin{array}{l}\text { No. area } \\
\text { with infected } \\
\text { snails(ha) }\end{array}$ & $\begin{array}{l}\text { No. } \\
\text { frames } \\
\text { surveyed }\end{array}$ & $\begin{array}{l}\text { No. } \\
\text { frames } \\
\text { with snails }\end{array}$ & $\begin{array}{l}\text { No. } \\
\text { dissected } \\
\text { living } \\
\text { snails }\end{array}$ & $\begin{array}{l}\text { No. } \\
\text { infected } \\
\text { snails }\end{array}$ & $\begin{array}{l}\text { Percentage of } \\
\text { frames with living } \\
\text { snails, \% }(95 \% \text { CI })\end{array}$ & $\begin{array}{l}\text { Infection rate, \% } \\
(95 \% \text { Cl) }\end{array}$ \\
\hline \multirow[t]{6}{*}{ । } & 2005 & 6966 & 5150 & 13 & 482 & 335391 & 56884 & 256531 & 663 & 16.96 (16.83-17.09) & $0.2584(0.2388-0.2781)$ \\
\hline & 2006 & 7462 & 5014 & 22 & 625 & 374149 & 47808 & 203828 & 744 & $12.78(12.67-12.88)$ & $0.3650(0.3388-0.3912)$ \\
\hline & 2007 & 7110 & 4603 & 1 & 244 & 356623 & 41927 & 152389 & 297 & $11.76(11.65-11.86)$ & $0.1949(0.1728-0.2170)$ \\
\hline & 2008 & 7372 & 4633 & 8 & 176 & 362537 & 32455 & 117615 & 178 & $8.95(8.86-9.05)$ & $0.1513(0.1291-0.1736)$ \\
\hline & 2009 & 7395 & 4570 & 0 & 134 & 360932 & 31964 & 121574 & 214 & $8.86(8.76-8.95)$ & $0.1760(0.1525-0.1996)$ \\
\hline & 2010 & 7087 & 4294 & 54 & 173 & 380727 & 29666 & 106107 & 187 & $7.79(7.71-7.88)$ & $0.1762(0.1510-0.2015)$ \\
\hline \multirow[t]{5}{*}{$\|$} & 2011 & 7009 & 4037 & 0 & 98 & 376348 & 24309 & 83775 & 117 & $6.46(6.38-6.54)$ & $0.1397(0.1144-0.1649)$ \\
\hline & 2012 & 6974 & 3859 & 0 & 4 & 398717 & 20748 & 73979 & 7 & $5.20(5.13-5.27)$ & $0.0095(0.0025-0.0165)$ \\
\hline & 2013 & 7157 & 4093 & 0 & 1 & 356279 & 18033 & 54091 & 1 & $5.06(4.99-5.13)$ & $0.0018(0.0000-0.0055)$ \\
\hline & 2014 & 7248 & 4100 & 0 & 0 & 423755 & 18121 & 66522 & 0 & $4.28(4.22-4.34)$ & 0.0000 \\
\hline & 2015 & 7571 & 4147 & 0 & 0 & 393597 & 28797 & 11617 & 0 & $7.32(7.24-7.40)$ & 0.0000 \\
\hline Total & & 79351 & 48500 & 98 & 1937 & 4119055 & 350712 & 1350028 & 2408 & - & - \\
\hline
\end{tabular}

ha hectare, $\mathrm{Cl}$ Confidence intervals 


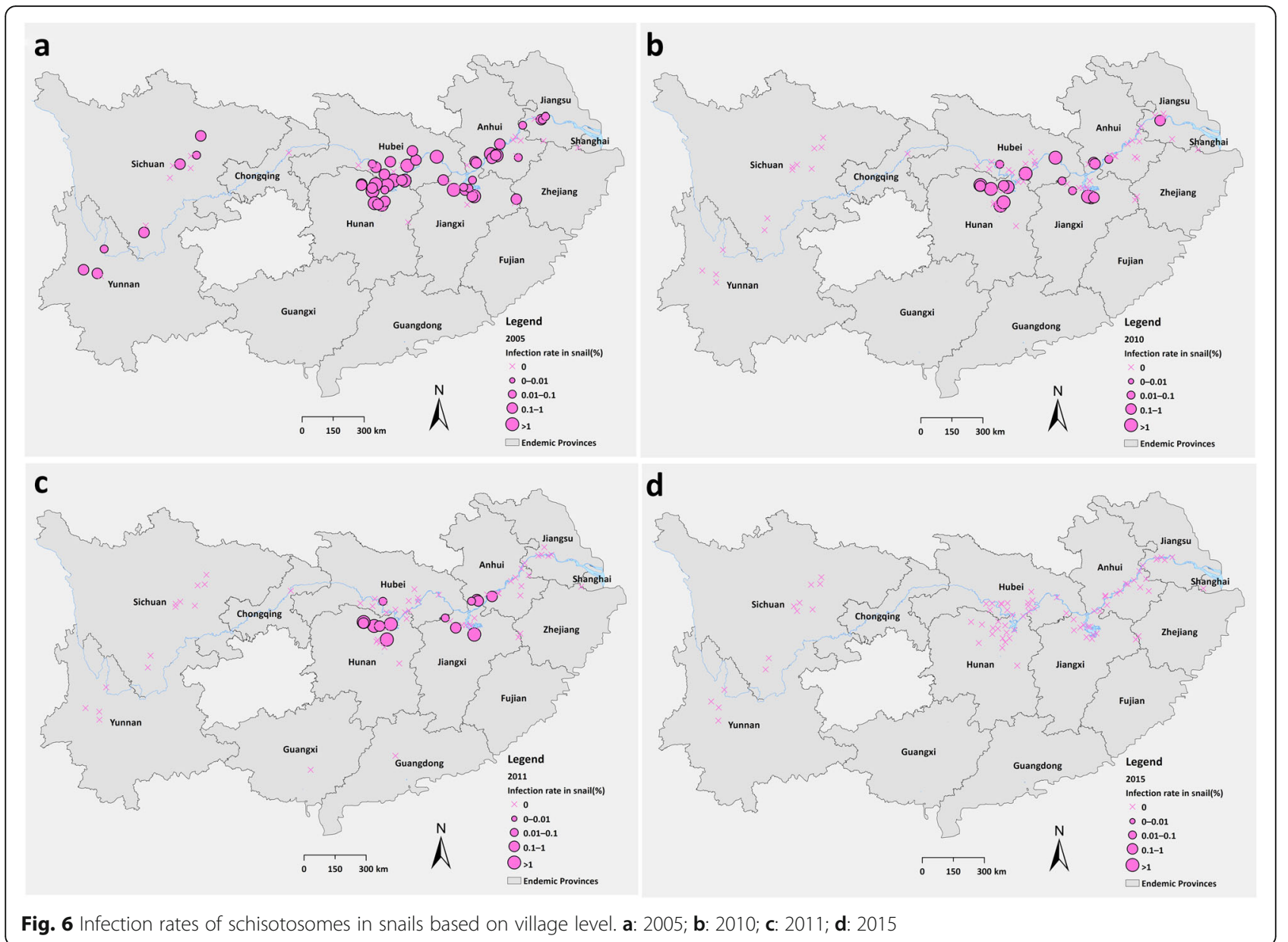

Measurement of the changes of infection rates of schistosomes in humans, livestock and snails could provide the best indication of the effectiveness of the interventions on schistosomiasis. The national sentinel surveillance conducted in 2005-2015 in P.R. China illustrated significant decline of transmission intensity and changes of transmission pattern due to continued interventions against schistosomiasis. The infection rate of schistosomes in residents decreased by more than $90 \%$ from 2005 to 2015. The decreased and delayed peak of infection rate in residents with age especially in 2015 may due to the lower transmission risk in living surroundings as fewer infected domestic animal and no infected snails detected, higher knowledge level towards schistosomiasis control and prevention in school-aged children or young adults by health education, or the changed population structure in rural areas as more young and mid-age adult moving to city over the past decades [27]. Fishermen and boatmen were the major population groups responsible for a large proportion of environmental contamination with Schistosoma eggs, due to their frequent water contact behavior [28]. The administration of chemotherapy or stool collection for these groups is very difficult due to their floating behavior and continuous water contact $[29,30]$. As there are more than 10 thousand fishermen and boatmen in the Poyang and Dongting Lake, respectively, new approaches targeted for this groups for blocking transmission are needed urgently when the national schistosomiasis programme moving towards elimination stage.

Schistosomiasis japonica is a zoonotic disease, as more than 40 species of domestic and wild animals acting as reservoir hosts of $S$. japonicum [31]. Chemotherapy was the major intervention against animal infection in P.R. China before 2004. Evidence showed that this approach could decrease the infection rate and morbidity of schistosomiasis in livestock to a relative low level, but couldn't prevent reinfection, particularly in the lake and marshland region [32]. With the implementation of integrated control measures, the infection rate of schistosomiasis in domestic animals declined by $99 \%$, and only two infected cattle detected in two villages of Hunan Province in 2015. Meanwhile, various domestic animals were detected stool positive at the beginning of surveillance while cattle always presented the higher positive rate according to the surveillance, which consistent with 
former studies proving bovines' role in the transmission of schistosomiasis [33, 34]. However, some studies investigated that dogs, goats or wild mice still played important roles on schistosomiasis transmission in some certain endemic areas where transmission of schistosomiasis had been under control or there were no domestic animal raised [35-37]. Understanding the major species of domestic and wild animals serving as reservoir hosts in local settings timely thus to take relevant countermeasures, are necessary to consolidate the achievements obtained and facilitate the progress towards schistosomiasis elimination.

Although snail control was neglected in most schistosomiasis endemic countries, it is an important intervention to interrupt the life cycle of Schistosoma to reduce the endemic range and transmission risk in P.R. China [6, 38, 39]. Through snail control approach, the area of snail habitats had decreased from about 1.43 million hectare in the 1950s to 0.38 million hectare by 2003 before the MLNP [3]. In our study, the decline of snail habitats was slowly and slightly from 2005 to 2015 in the sentinel sites, but the areas of infected snails, the density of snails and infection rate of schistosomes in snails were significantly decreased, thus lowered the risk of schistosomiasis transmission [40]. The recent publication also demonstrated snail control is an important component of the national schistosomiasis control strategy [41]. In addition, a total of 98 ha of new snail habitats had been explored in sentienl sites during 20052015, which mostly distributed in the lake and marshland regions, proved once again the difficulty in eliminating an amphibious species-Oncomelania hupensis, but we are able to eliminate the infected snails $[27,40,42,43]$.

Based on the evidence obtained from the sentinel sites, in combination with the annual data obtained from endemic provinces, P.R. China has reached the final goal set by the MLNP to reach the transmission control, also eliminate schistosomiasis as a public health problem one year earlier than the deadline settled by WHO Western Pacific Region Office [6, 44, 45], and it is also only one country reached this goal by 2020 in Western Pacific Region. The strategic plan of Healthy China 2030 issued by Chinese government set the goal of eliminating schistosomiasis nationwide by 2030 [46]. To reach the final goal of schistosomiasis elimination, mechanisms of multi-sector cooperation and government leader role should be insisted to ensure the available resources for schistosomiasis control efforts in all endemic regions. During the transition stage from control to elimination, effective control activities should be conducted more precisely due to the changes of transmission pattern and heterogenous endemicity of schistosomiasis, supported by the precise tools or technologies [47, 48].

Contradictory with the decreased trend of infection rates based on sentinel surveillance data, we also noticed that challenges existed to eliminate schistosomiasis nationwide especially in the areas around the Dongting Lake and Poyang Lake, due to the large areas of snail habitats, newly developed snails infested areas, large amount of fishermen and boatmen, various animal reservoir hosts etc. As elimination of a disease is defined as reducing a locally acquired infection to zero incidence in a specific, geographic area through deliberate efforts, surveillance and response systems appear to be the most cost-effective way to improve the efficiency in the disease elimination $[49,50]$. As surveillance has been major important intervention in the national schistosomiasis elimination program in P.R. China, surveillance-response systems should be further improved and strengthened through developing and implementing effective and precise tools for surveillance, owning a well-trained team for case finding, data reporting, foci tracking and rapid action, improving the accuracy and timeliness of data collection, analysis, interpretation and early warning systems, tailoring precise surveillance activities into local situations. The sensitive and effective surveillanceresponse systems will not only promote the process of schistosomiasis towards elimination, but also provide scientific evidence for schistosomiasis elimination programme in P.R. China.

Several limitations of this study should be noted. One is the adjustment of sentinel sites in the year of 2011, by which the surveillance data may result in a biased sample and participants although the eco-epidemiological feature and numbers of sentinel sites from each province are almost the same between two phases. The other one is the representation of the residents participated in the investigation, in which the population structure and movement were not considered as biased factors in the data analysis, so the infection rate we obtained is the crude value that only can used for observing the change patterns. In addition, only four or five sentinel sites were selected from provinces where transmission had been interrupted, the average infection rate based on the sentinel surveillance data was overestimated compared to the real value at national level.

\section{Conclusions}

Eleven years of surveillance data presented the decreased trends of infection rates of schistosomes in residents, domestic animals and snails, with the implementation of the integrated control strategy. Elimination of schistosomiasis as a public health problem was reached in P.R. China nationwide according to WHO's definition. With the changes of transmission features and existed challenges for schistosomiasis elimination, surveillanceresponse systems should be further improved and strengthened in P.R. China in order to achieve the goal of schistosomiasis elimination by 2030 . 


\section{Abbreviations}

CDC: Center for Disease Control; Cl: Confidence intervals; EPG: Eggs per gram feces; $H T$ : Hatching technique; IHA: Indirect hemagglutination assay; KK: Katokatz method; MLNP: The Medium and long term national plan; P.R. China: People's Republic of China; WHO: World Health Organization

\section{Acknowledgements}

We are grateful to all the staff from provincial schistosomiasis control institutes, schistosomiasis control stations at county level, village leaders who performed the study; and the population of the villages for their participation.

\section{Authors' contributions}

J Xu and XN Zhou participated in manuscript writing design. J Xu, SZ Li and $R$ Bergquist did the search of literature and wrote the first draft. XN Zhou, R Bergquist revised the manuscript, and provided important intellectual content. TP Wang, DD Lin, JB Liu, GH Ren, K Yang, Y Liu, Y Dong and SQ Zhang organized the field work and participated in data collection. $L$ Z Zhang, H Dang, Q Wang, S LV participated in data collection and figure drawing. All authors have approved the final manuscript for publication.

\section{Funding}

This study was financially supported by the Natural Science Foundation of China (No. 30590373) and the National Special Science and Technology Project for Major Infectious Diseases of China (No. 2012ZX10004-220, 2016YFC1202000).

\section{Availability of data and materials}

All data generated or analyzed during this study are confidentially kept at the National Institute of Parasitic Disease, Chinese Center for Disease Control and Prevention. The datasets are available from the corresponding author on a reasonable request.

\section{Ethics approval and consent to participate}

This paper was based on analysis of routine collected surveillance data from NIPD, China CDC. Program leadership and staff led the review, analysis and interpretation of the data. No individual information was revealed.

\section{Consent for publication}

Not applicable.

\section{Competing interests}

XNZ is the Editor-in-Chief of the journal Infectious Diseases of Poverty.

\section{Author details}

${ }^{1}$ National Institute of Parasitic Diseases, Chinese Center for Disease Control and Prevention, WHO Collaborating Centre for Tropical Diseases, Chinese Center for Tropical Disease Research, Shanghai 200025, People's Republic of China. ${ }^{2}$ Geospatial Health, Ingerod 407, S-45494 Brastad, Sweden. ${ }^{3}$ Anhui Provincial Institute of Schistosomiasis Control, Hefei, Anhui Province 230061 People's Republic of China. ${ }^{4}$ Jiangxi Provincial Institute of Parasitic Disease, Nanchang, Jiangxi Province 330006, People's Republic of China. ${ }^{5}$ Hubei Provincial Institute of Schistosomiasis Control, Hubei Center for Disease Control, Wuhan, Hubei Province 430079, People's Republic of China. ${ }^{6}$ Hunan Provincial Institute of Schistosomiasis Control, Yueyang, Hunan Province 414000, People's Republic of China. ${ }^{7}$ Jiangsu Provincial Institute of Schistosomiasis Control, Wuxi, Jiangsu Province 214064, People's Republic of China. ${ }^{8}$ Sichuan Center for Disease Control, Chengdu, Sichuan Province 610041, People's Republic of China. ${ }^{9}$ Yunnan Provincial Institute of Endemic Diseases Control and Prevention, Dali, Yunnan Province 671000, People's Republic of China.

\section{Received: 10 March 2020 Accepted: 19 May 2020}

Published online: 06 June 2020

\section{References}

1. Colley DG, Bustinduy AL, Secor WE, King CH. Human schistosomiasis. Lancet. 2014;383(9936):2253-64.

2. Lin JJ, Hu SG, Liu JM. Control of domestic animal schistosomiasis japonica in China. Chin J Anim Infect Dis. 2011;19:75-81 (in Chinese).
3. Zhou XN, Wang LY, Chen MG, Wu XH, Jiang QW, Chen XY, et al. The public health significance and control of schistosomiasis in China--then and now. Acta Trop. 2005;96(2-3):97-105.

4. Chen M. Progress in schistosomiasis control in China. Chin Med J. 1999: 112(10):930-3.

5. Bundy DA, Gottlieb M. Parasitic infection in China: farewell to the god of plagues. Parasitol Today. 1999;15(5):170-2.

6. Xu J, Steinman P, Maybe D, Zhou XN, Lv S, Li SZ, et al. Evolution of the National Schistosomiasis Control Programmes in the People's Republic of China. Adv Parasitol. 2016;92:1-38.

7. Xu J, Xu JF, Li SZ, Zhang L, Wang Q, Zhu HH, et al. Integrated control programmes for schistosomiasis and other helminth infections in P.R. China. Acta Trop. 2015;141:332-41.

8. Chen XY, Wang LY, Cai JM, Zhou XN, Zheng J, Guo JG, et al. Schistosomiasis control in China: the impact of a 10-year World Bank loan project (19922001). Bull World Health Organ. 2005;83(1):43-8.

9. Wang LD, Chen HG, Guo JG, Zeng XJ, Hong XL, Xiong JJ, et al. A strategy to control transmission of Schistosoma japonicum in China. $N$ Engl J Med. 2009:360(2):121-8.

10. WHO. Progress report 2001-2011 and strategic plan 2012-2020: World Health Organization; 2012. https://www.who.int/schistosomiasis/resources/ 9789241503174/en/. Accessed 6 Apr 2012.

11. Zhang LJ, Li SZ, Wen LY, Lin DD, Abe EM, Zhu R, et al. The establishment and function of schistosomiasis surveillance system towards elimination in the People's Republic of China. Adv Parasitol. 2016;92:117-41.

12. Zhao GM, Zhao Q, Jiang QW, Chen XY, Wang LY, Yuan HC. Surveillance for schistosomiasis japonica in China from 2000 to 2003. Acta Trop. 2005;96(23):288-95.

13. Zhu R, Zhao G, Li H, Guo J. Development and prospect of surveillance network of schisotosmiasis in China. Chin J Schis Control. 2011;23(1):1-17 (in Chinese)

14. Mao SP. Epidemiology and control of schistosomiasis in the People's Republic of China. Mem Inst Oswaldo Cruz. 1987:82(Suppl 4):77-82.

15. Zhou XN, Xu J, Chen HG, Wang TP, Huang XB, Lin DD, et al. Tools to support policy decisions related to treatment strategies and surveillance of schistosomiasis japonica towards elimination. PLoS Negl Trop Dis. 2011; 5(12):e1408

16. Ministry of Health. Handbook for schistosomiasis. 3rd ed. Shanghai: Shanghai Science \&Technology Press; 2000.

17. Katz N, Chaves A, Pellegrino J. A simple device for quantitative stool thicksmear technique in schistosomiasis mansoni. Rev Inst Med Trop Sao Paulo. 1972:14:397-40.

18. Dang H, Zhu R, Guo JG. Report of the result of national surveillance for schistosomiasis in China, 2005. J Trop Dis Parasitol. 2006:4(4):189-92,96.

19. Dai SM, Edwards J, Guan Z, Lv S, Li SZ, Zhang LJ, et al. Change patterns of oncomelanid snail burden in areas within the Yangtze River drainage after the three gorges dam operated. Infect Dis Poverty. 2019; 8(1):48.

20. WHO. Summary of global update on preventive chemotherapy implementation in 2015. Wkly Epidemiol Rec. 2016;91:456-9.

21. Savioli L, Fenwick A, Rollinson D, Albonico M, Ame SM. An achievable goal: control and elimination of schistosomiasis. Lancet. 2015;386(9995): 739.

22. Ross AG, Olveda RM, Li Y. An audacious goal: the elimination of schistosomiasis in our lifetime through mass drug administration. Lancet. 2015;385:2220-1.

23. Tchuem Tchuente LA, Rollinson D, Stothard JR, Molyneux D. Moving from control to elimination of schistosomiasis in sub-Saharan Africa: time to change and adapt strategies. Infect Dis Poverty. 2017;6(1):42.

24. Rollinson D, Knopp S, Levitz S, Stothard JR, Tchuem Tchuente LA, Garba A, et al. Time to set the agenda for schistosomiasis elimination. Acta Trop. 2013;128(2):423-40.

25. Hao Y, Wu XH, Xia G, Zheng H, Guo JG, Wang LY, et al. Schistosomiasis situation in People's Republic of China in 2005. Chin J Schisto Contr. 2006; 18(5):321-4 (in Chinese)

26. Zhang LJ, Xu ZM, Qian YJ, Dang H, Lv S, Xu J, et al. Endemic status of schistosomiasis in People's republic of China in 2015. Chin J Schisto Contr. 2016;28(6):611-7 (in Chinese).

27. Zhou YB, Liang S, Jiang QW. Factors impacting on progress towards elimination of transmission of schistosomiasis japonica in China. Parasit Vectors. 2012;5:275. 
28. Guan Z, Lv S, Li SZ, Dang H, Zhang LJ, Xu J. Analysis on the situation of schistosome infections in floating population in national schistosomiasis surveillance sites of China. Chin J Schisto Control. 2018;30(2):124-30.

29. Zhou J, Huang CY, He YK, Du YQ, Yu XL, Wang YY, et al. Epidemiological evaluation of schistosomiasis in migrant fishermen in Dongting Lake region. Chin J Schisto Control. 2010;22(5):70-3 (in Chinese).

30. Yu XL, Zhou J, He YK, Huang MZ, Li YS. Influence factors of Schistosoma japonicum infection among fishermen in eastern Dongting Lake region. Chin J Parasitol Parasit Dis. 2013;31(4):307-9 (in Chinese).

31. Cao ZG, Zhao YE, Lee Willingham A, Wang TP. Towards the elimination of schistosomiasis japonica through control of the disease in domestic animals in the People's Republic of China: a tale of over 60 years. Adv Parasitol. 2016;92:269-306.

32. Wang T, Zhang S, Wu W, Zhang G, Lu D, Ornbjerg N, et al. Treatment and reinfection of water buffaloes and cattle infected with Schistosoma japonicum in Yangtze River valley, Anhui province, China. J Parasitol. 2006; 92(5):1088-91.

33. Guo JG, Ross AG, Lin DD, Williams GM, Chen HG, Li Y, et al. A baseline study on the importance of bovines for human Schistosoma japonicum infection around Poyang Lake, China. Am J Trop Med Hyg. 2001;65(4):272-8.

34. Gray DJ, Williams GM, Li Y, McManus DP. Transmission dynamics of Schistosoma japonicum in the lakes and marshlands of China. PLoS One. 2008;3(12):e4058.

35. Li K, Cai SX, Tang L, Wan L, Shan XW, Li B. Research on epidemic factors after schistosomiasis transmission being under control in Hubei Province. J Pub Health Prev Med. 2018;29(163):123-6 (in Chinese).

36. Lin JJ. Strengthening the control of goat schistosomiasis to facilitate the progress towards elimination of schistosomiasis in China. Chin J Schis Control. 2016;28(5):481-3 (in Chinese).

37. Wang CF, Wang CX, Wang SZ, Mu LR, Wu ZS, Lu GJ. Investigation on epidemic factors after schistosomiasis transmission controlled in Lushan County. Chin J Schis Control. 2013;25(1):64-6 (in Chinese).

38. Li ZJ, Ge J, Dai JR, Wen LY, Lin DD, Madsen H, et al. Biology and control of snail intermediate host of Schistosoma japonicum in the People's Republic of China. Adv Parasitol. 2016;92:197-236.

39. Guan W, Hong QB, Lv S, Xu J, Li SZ. Research progress of control technique on Oncomelania hupensis. Chin J Schisto Control. 2017;29(2):246-51 (in Chinese).

40. Zhou YB, Chen Y, Liang S, Song XX, Chen GX, He Z, et al. Multi-host model and threshold of intermediate host Oncomelania snail density for eliminating schistosomiasis transmission in China. Sci Rep. 2016;6:31089.

41. Lo NC, Gurarie D, Yoon N, Coulibaly JT, Bendavid E, Andrews JR, et al. Impact and cost-effectiveness of snail control to achieve disease control targets for schistosomiasis. Proc Natl Acad Sci U S A. 2018;115(4):E584-E91.

42. Wu XH, Zhang SQ, Xu XJ, Huang YX, Steinmann P, Utzinger J, et al. Effect of floods on the transmission of schistosomiasis in the Yangtze River valley, People's Republic of China. Parasitol Int. 2008;57(3):271-6.

43. Yang GJ, Zhou XN, Sun LP, Wu F, Zhong B, Qiu DC, et al. Compensatory density feedback of Oncomelania hupensis populations in two different environmental settings in China. Parasit Vectors. 2011:4:133.

44. WPRO. Regional action plan for neglected tropical diseases in the Western Pacific Region (2012-2016): WHO Regional Office for the Western Pacific; 2013. http://iris.wpro.who.int/handle/10665.1/5286. Accessed 6 Apr 2013

45. Zhang LJ, Dai SM, Xue JB, Li YL, Lv S, Xu J, et al. The epidemiological status of schistosomiasis in P. R. China after the World Bank loan project, 20022017. Acta Trop. 2019;195:135-41.

46. State Council of China. The strategic plan healty China 2030. 2016. http://www. gov.cn/zhengce/2016-10/25/content_5124174.htm. Accessed 31 Jan 2016.

47. Xu J, Lv S, Cao CL, Li SZ, Zhou XN. Progress and challenges of schistosomiasis elimination in China. Chin J Schis Control. 2019;30(6):605-8 (in Chinese).

48. Zhou XN. Implementation of precision control to achieve the goal of schistosomiasis elimination in China Chin J Schis. Control. 2016;28(1):1-4 (in (hinese).

49. Tambo E, Ai L, Zhou X, Chen JH, Hu W, Bergquist R, et al. Surveillanceresponse systems: the key to elimination of tropical diseases. Infect Dis Poverty. 2014;3:17

50. Zhou X, Yap P, Tanner M, Bergquist R, Utzinger J, Zhou XN. Surveillance and response systems for elimination of tropical diseases: summary of a thematic series in Infectious Diseases of Poverty. Infect Dis Poverty. 2016;5(1):49.

Ready to submit your research? Choose BMC and benefit from:

- fast, convenient online submission

- thorough peer review by experienced researchers in your field

- rapid publication on acceptance

- support for research data, including large and complex data types

- gold Open Access which fosters wider collaboration and increased citations

- maximum visibility for your research: over $100 \mathrm{M}$ website views per year

At $\mathrm{BMC}$, research is always in progress.

Learn more biomedcentral.com/submissions 